\title{
Perbandingan Faktor-Faktor yang Mempengaruhi Pengetahuan Tentang Asi Ekslusif Antara Ibu yang Melahirkan di BPM Dengan Puskesmas
}

\author{
Heriza Syam $^{1}$, Jehanara ${ }^{2}$, Nurdjasmi ${ }^{3}$ \\ 12,3 Jurusan Kebidanan Poltekkes Kemenkes Jakarta III
}

\begin{tabular}{l}
\hline ARTICLE INFORMATION \\
\hline Article Trace \\
Submission: January, 13, 2019 \\
Final Revision: March 21, 2019 \\
Available online: April 20, 2019 \\
\hline
\end{tabular}

\section{Kata kunci :}

Pengetahuan, ASI Ekslusif, Praktik Mandiri Bidan, Puskesmas

Key Word :

Knowledge, exclusive breasting, Midwife Independent Practices, Puskesmas

Contact:

herizasyam@gmail.com

\begin{abstract}
A B S T R A K
Pengetahuan ibu semenjak hamil menjadi salah satu factor dalam keberhasilan ASI eksklusif. Penelitian di Ghana dalam jurnal Pediatrics tahun 2008 menunjukkan 1,3 juta kematian bayi dapat dicegah dengan pemberian Air Susu Ibu (ASI) pada bayi sejak hari pertama kelahirannya sampai berusia di bawah 5 tahun. Angka ini naik menjadi $22 \%$ dari $16 \%$, jika pemberian ASI dimulai dalam 1 jam pertama setelah kelahirannya. Penelitian ini bertujuan untuk mengetahui perbedaan pengetahuan tentang ASI Ekslusif dan fator-faktor yang mempengaruhinya pada ibu post partum di BPM dengan Puskesmas di wilayah Jakarta Timur Desain Penelitian: studi analitik observasional dengan pendekatan yang digunakan adalah cross sectional. Hasil penelitian menunjukkan bahwa terdapat perbedaan yang signifikan $(\mathrm{P}=0,001)$ antara tempat persalinan dengan pengetahuan ibu menyusui. Ibu yang bersalin di Praktik Bidan Mandiri (PMB) berpengetahuan baik sebanyak $78,6 \%$, sedangkan yang di Puskesmas yang hanya 38,5\%. Karakteristik responden yang berhubungan dengan pengetahuan ibu post partum tentang menyusui adalah Pendidikan (P 0,01), Ekonomi, ( $\mathrm{P}$ 0,000) dan suku bangsa (P 0,019). Faktor-pendidikan, ekonomi dan suku bangsa mempengaruhi pengetahuan ibu tentang ASI ekslusif. Tempat persalinan di Praktek Mandiri Bidan mempunyai peluang dalam peningkatan pengetahuan ASI Ekslusif ibu sebanyak 3 kali dibandingkan dengan pengetahuan ibu yang bersalin di Puskesmas setelah dikontrol variabel Pendidikan.
\end{abstract}

\begin{abstract}
A B S T R A C T
Mother's knowledge is one factor in the success of exclusive breastfeeding. Research in Ghana (2008), 1.3 million infant deaths can be prevented by the provision of breast milk (ASI) in infants from the first day of birth until under the age of 5 years. If breastfeeding starts in the first 1 hour after birth, This figure rises to $22 \%$ from $16 \%$,. This study aims to determine the differences in knowledge about Exclusive Breastfeeding and the factors that influence it in post partum mothers in BPM with Puskesmas in the East Jakarta area. Research Design: Observational analytic study with the approach used is cross sectional. The results showed that there were significant differences $(P=0.001)$ between the place of labor and the knowledge of nursing mothers. Mothers who gave birth at the Good Knowledge Midwife Practice (PMB) were $78.6 \%$, while those in the Puskesmas were only $38.5 \%$. Characteristics of respondents related to knowledge of post partum mothers about breastfeeding were Education ( $\mathrm{P}$ 0.01), Economy, ( $\mathrm{P}$ 0.000 ) and ethnicity (P 0.019). Factors-education, economy and ethnicity influence mother's knowledge about exclusive breastfeeding. Place of birth in the Independent Practice Midwives have the opportunity to increase knowledge of exclusive breastfeeding 3 times compared to the knowledge of mothers who give birth at the Puskesmas after controlled by the Education variable.
\end{abstract}




\section{PENDAHULUAN}

Perilaku pemberian ASI eksklusif secara global masih rendah, dilihat dari cakupan pemberian ASI . Menurut data WHO (2016), cakupan ASI eksklusif di seluruh dunia hanya sekitar 36\% selama periode 2007-2014. Berdasarkan hasil Riskesdas (2012), cakupan pemberian ASI eksklusif di Indonesia sebesar 54,3\%,. World Health Organization (WHO) dan United Nations Childrens Fund (UNICEF) merekomendasikan agar ibu menyusui bayinya saat satu jam pertama setelah melahirkan dan melanjutkan hingga usia 6 bulan pertama kehidupan bayi.

Berdasarkan profil kesehatan Indonesia tahun 2016. Persentase bayi 0-5 bulan yang masih mendapat ASI eksklusif sebesar 54,0\%, sedangkan bayi yang telah mendapatkan ASI eksklusif sampai usia enam bulan adalah sebesar 29,5\%. Mengacu pada target renstra tahun 2016 yang sebesar $42 \%$, maka secara nasional cakupan pemberian ASI eksklusif pada bayi usia kurang dari enam bulan sebesar 54,0\% telah mencapai target.(Kemenkes RI, 2016). Salah satu faktor yang mempengaruhi dalam pemberian ASI adalah dukungan tenaga kesehatan yang adekuat. Dukungan fasilitas pelayanan kesehatan dan bidan sebaiknya diberikan mulai dari pusat pelayanan primer hingga pusat pelayanan tersier, dari Rumah Sakit tingkat nasional hingga posyandu dan polindes di tingkat RT/RW/Kelurahan/Desa perlu terus meningkatkan sosialisasi dan penerapan ASI eksklusif (Ariwati, 2014). Hasil penelitian Hutton (2009) di Kanada memperlihatkan bahwa lebih banyak bayi yang menyusui secara ekslusif pada ibu yang melahirkan dirumah dibandingkan yang melahirkan di rumah sakit. Hasil studi di Belanda tahun 2000-2002 pada 9133 bayi terlihat bahwa ibu yang melahirkan dirumah dengan bidan lebih tinggi tingkat inisiasi menyusui serta durasi menyusui lebih lama dibandingkan dengan melahirkan di Rumah Sakit.

Tujuan penelitian ini adalah untuk mengetahui perbedaan pengetahuan tentang menyusui pada ibu yang melahirkan di Praktik Bidan Mandiri dan Puskesmas serta mengidentifikasi perbedaan faktor-faktor yang mempengaruhi pengetahuan tentang ASI Ekslusif antara ibu yang melahirkan di BPM dengan Puskesmas.

\section{METODE}

Desain penelitian ini menggunakan studi analitik observasional dengan pendekatan yang digunakan adalah cross sectional. Populasi terjangkau adalah penelitian ini adalah semua ibu post partum 0-1 minggu di wilayah Puskesmas Jakarta Timur dan BPM Jakarta Timur yang memenuhi kriteria inklusi dan eksklusi serta bersedia menjadi responden penelitian dengan menandatangani lembar persetujuan (informed concent). Jumlah sampeldalam penelitian ini sebanyak 82 orang. Tehnik pengambilan sampel pada penelitian ini adalah Random sampel untuk menentukan tempat Puskesmas. Hasil random terpilih Puskesmas Kecamatan Kramat Jati dan Ciracas. Untuk sampel ibu hamil dan menyusui menggunakan teknik purpusive sampling. yaitu semua subyek yang datang dan memenuhi kriteria pemilihan dimasukkan dalam penelitian.

Populasi terjangkau dalam penelitian ini adalah semua ibu hamil dengan usia kehamilan $\geq 28$ minggu, yang ikut kelas antenatal di wilayah Puskesmas Jakarta Timur .Sampel pada penelitian ini sebanyak 40 responden yang memenuhi kriteria inklusi dan eksklusi di Puskesmas Kecamatan Cipayung dan Puskesmas Kecamatan Makassar.

\section{HASIL DAN PEMBAHASAN}

Tabel 1. Karakteristik Subjek penelitian

\begin{tabular}{|c|c|c|c|c|}
\hline \multirow[t]{2}{*}{ Karakteristik } & \multicolumn{2}{|c|}{$\begin{array}{l}\text { Praktik Bidan } \\
\text { Mandiri }\end{array}$} & \multicolumn{2}{|c|}{ Puskesmas } \\
\hline & $\mathbf{n}$ & $\%$ & $\mathbf{n}$ & $\%$ \\
\hline \multicolumn{5}{|l|}{ Usia } \\
\hline$<30$ tahun & 30 & 71,4 & 28 & 71,8 \\
\hline$\geq 30$ tahun & 12 & 28,6 & 11 & 28,2 \\
\hline \multicolumn{5}{|l|}{ Pendidikan } \\
\hline Pendidikan Tinggi & 36 & 85,7 & 22 & 56,4 \\
\hline Pendidikan Rendah & 6 & 14,3 & 17 & 43,6 \\
\hline \multicolumn{5}{|l|}{ Pekerjaan } \\
\hline Tidak Bekerja & 29 & 69 & 20 & 51,3 \\
\hline Bekerja & 13 & 31 & 19 & 48,7 \\
\hline \multicolumn{5}{|l|}{ Paritas } \\
\hline Primipara & 16 & 38,1 & 17 & 43,6 \\
\hline Multipara & 26 & 61,9 & 22 & 56,4 \\
\hline \multicolumn{5}{|l|}{ Ekonomi } \\
\hline$\geq \mathrm{UMR}$ & 33 & 78,6 & 11 & 28,2 \\
\hline$<$ UMR & 9 & 21,4 & 28 & 71,8 \\
\hline \multicolumn{5}{|l|}{ Suku } \\
\hline Betawi /sunda & 18 & 42,9 & 17 & 43,6 \\
\hline Jawa & 15 & 35,7 & 19 & 48,7 \\
\hline Di luar pulau jawa & 9 & 21,4 & 3 & 7,7 \\
\hline Jumlah & 42 & 100 & 39 & 100 \\
\hline
\end{tabular}


Perbandingan Faktor-Faktor Yang Mempengaruhi Pengetahuan Tentang........

Berdasarkan tabel 1.1 dapat diketahui bahwa karakteristik responden pada Praktik Mandiri Bidan (PMB) dengan Puskesmas memiliki karakteristik yang hampir sama. Usia subjek penelitian paling banyak berusia dibawah 30 tahun (PMB sebanyak 30 orang atau 71,4\%; PKM sebanyak 28 orang atau 71,8\%). Tingkat pendidikan responden paling banyak berada pada lulusan tingkat pendidikan tinggi (PMB sebanyak 36 orang atau $85,7 \%$; PKM sebanyak 22 orang atau 56,4\%). Responden penelitian lebih banyak yang tidak bekerja/ibu rumah tangga sebanyak 29 orang atau 69\% (PMB) dan Puskesmas sebanyak 20 orang atau 51,3\% (PKM). Mayoritas responden adalah multipara, sebanyak 26 orang $(61,9 \%)$ sedangkan Puskesmas sebanyak 22 orang (56,4\%). Karakteristik responden yang berbeda antara Praktek Mandiri Bidan dengan Puskesmas hanya terlihat dari suku yaitu suku betawi dan sunda yang paling banyak di Bidan Praktik Mandiri sebanyak 18 orang $(42,9 \%)$, sedangkan subjek di Puskesmas paling banyak adalah suku Jawa sebanyak 19 orang $(48,7 \%)$. Hasil univariat untuk variabel penelitian Pengetahuan dan Teknik penyusuan tampak pada table 2 .

Pada table 2 dapat diketahui pada kelompok Bidan Praktik Mandiri pengetahuan subjek penelitian tentang ASI ekslusif dan teknik penyusuan paling banyak pada kategori baik yaitu 78,6 \%. Hal ini berbeda pada kelompok Puskesmas, berpengetahuan baik hanya 38,5\%.

Hasil analisis Bivariat variabel karakteristik subjek /konfounding dengan variabel pengetahuan adalah sebagai berikut:

Tabel 2. Deskripsi Variabel Penelitian berdasarkan tingkat pengetahuan

\begin{tabular}{lccccc}
\hline $\begin{array}{c}\text { Variabel } \\
\text { penelitian }\end{array}$ & $\begin{array}{c}\text { Praktik Bidan Mandiri } \\
\text { (PMB) }\end{array}$ & $\begin{array}{c}\text { Puskesmas } \\
\text { (PKM) }\end{array}$ & \multicolumn{2}{c}{ TOTAL } \\
& n & $\%$ & n & N & $\%$ \\
\hline Pengetahuan & & & & & \\
Baik & 33 & 78,6 & 15 & 48 & 38,5 \\
Kurang & 9 & 21,4 & 24 & 33 & 61,5 \\
$\quad$ Jumlah & 42 & 100 & 39 & 81 & 100 \\
\hline
\end{tabular}

Tabel 3. Hubungan variabel Karateristik subjek penelitian dengan Pengetahuan ASI eksklusif

\begin{tabular}{|c|c|c|c|c|c|c|c|c|}
\hline \multirow{3}{*}{ Umur } & \multicolumn{4}{|c|}{ Pengetahuan tentang ASI eksklusif } & \multirow{2}{*}{\multicolumn{2}{|c|}{ Total }} & \multirow{3}{*}{ OR $(95 \% \mathrm{CI})$} & \multirow{3}{*}{$\begin{array}{c}P \\
\text { value }\end{array}$} \\
\hline & \multicolumn{2}{|c|}{ Baik } & \multicolumn{2}{|c|}{ Kurang } & & & & \\
\hline & $\mathrm{n}$ & $\%$ & $\mathrm{n}$ & $\%$ & $\mathrm{~N}$ & $\%$ & & \\
\hline \multirow{3}{*}{$\begin{array}{l}\text { Usia } \\
\quad<30 \\
\text { tahum } \\
\quad \geq 30 \\
\text { tahum } \\
\text { Pendidikan }\end{array}$} & & & & & & & \multirow{3}{*}{$1,5(0,5-3,9)$} & \multirow{3}{*}{0,57} \\
\hline & 36 & 62,1 & 22 & 37,9 & 58 & 100 & & \\
\hline & 12 & 52,2 & 11 & 47,8 & 23 & 100 & & \\
\hline $\begin{array}{l}\text { Pendidikan } \\
\text { tinggi }\end{array}$ & 40 & 34,4 & 18 & 23,6 & 58 & 100 & $\begin{array}{c}4,167(1,4- \\
11,5)\end{array}$ & 0,01 \\
\hline $\begin{array}{l}\text { Pendidikan } \\
\text { rendah } \\
\text { Pekerjaan }\end{array}$ & 8 & 34,8 & 15 & 65,2 & 23 & 100 & & \\
\hline $\begin{array}{r}\text { Tidak } \\
\text { Bekeria }\end{array}$ & 32 & 65,3 & 17 & 34,7 & 49 & 100 & \multirow{2}{*}{$1,882(0,7-4,7)$} & \multirow{2}{*}{0,26} \\
\hline $\begin{array}{l}\text { Bekerja } \\
\text { Paritas }\end{array}$ & 16 & 50 & 16 & 50 & 32 & 100 & & \\
\hline Primipara & 23 & 69,7 & 10 & 30,3 & 33 & 100 & \multirow{2}{*}{$2,116(0,8-5,3)$} & \multirow{2}{*}{0,18} \\
\hline Multipara & 25 & 52,1 & 23 & 47,9 & 48 & 100 & & \\
\hline \multicolumn{9}{|l|}{ Ekonomi } \\
\hline$\geq \mathrm{UMR}$ & 35 & 79,5 & 9 & 26,5 & 44 & 100 & $7,179(2,6-$ & 0000 \\
\hline$<\mathrm{UMR}$ & 13 & 35,1 & 24 & 64,9 & 37 & 100 & $19,4)$ & 0,000 \\
\hline
\end{tabular}


Tabel 1.4 Hubungan Tempat Bersalin dengan Pengetahuan Asi Ekslusif

\begin{tabular}{|c|c|c|c|c|c|c|c|c|}
\hline \multirow{3}{*}{$\begin{array}{l}\text { Tempat } \\
\text { Bersalin }\end{array}$} & \multicolumn{4}{|c|}{ Pengetahuan } & & & \multirow{3}{*}{$\begin{array}{c}\text { OR } \\
(95 \% \mathrm{CI})\end{array}$} & \multirow{3}{*}{$\begin{array}{c}\text { P } \\
\text { Value }\end{array}$} \\
\hline & \multicolumn{2}{|c|}{ Baik } & \multicolumn{2}{|c|}{ Kurang } & \multicolumn{2}{|c|}{ Total } & & \\
\hline & $\mathrm{n}$ & $\%$ & $\mathrm{n}$ & $\%$ & $\mathrm{~N}$ & $\%$ & & \\
\hline PMB & 33 & 78,6 & 9 & 21,4 & 42 & 100 & & \\
\hline & & & & & & & $5,867(2,2-15,6)$ & 0,001 \\
\hline Puskesmas & 15 & 38,5 & 24 & 61,5 & 39 & 100 & & \\
\hline Jumlah & 48 & 59,3 & 33 & 40,7 & 81 & 100 & & \\
\hline
\end{tabular}

Berdasarkan tabel $\quad 3$ variabel confounding/karakteristik subjek yang mempengaruhi pengetahuan ibu adalah Pendidikan dan ekonomi (pendapatan keluarga perbulan). Hal ini terlihat pada nilai $\mathrm{P}$ pada variabel Pendidikan yaitu 0,001 , dan nilai $\mathrm{P}$ pada variabel Ekonomi yaitu 0,000. Karakteristik subjek yang lain tidak berhubungan dengan pengetahuan ibu tentang ASI ekslusif, hal ini terlihat dari nilai $\mathrm{P}>0,005$.

Tabel 4 memperlihatkan hubungan yang kuat antara tempat persalinan dengan pengetahuan ibu tentang ASI ekslusif ( $\mathrm{P}=0,001)$, dengan nilai $\mathrm{OR}=5,867$

\section{PEMBAHASAN}

Pada kelompok ibu post partum di BPM dengan Puskesmas hasil univariat pada karakteristik subjek penelitian tidak terlalu berbeda jauh, yaitu usia paling banyak pada rentang kurang dari 30 tahun, pendidikan paling banyak adalah pendidikan tinggi, paling banyak ibu yang tidak bekerja dan paritas yang paling banyak adalah multipara. Pada karakteristik suku pada kelompok ibu post partum di BPM paling banyak suku betawi/sunda(42,0\%), sedangkan pada ibu post partum di Puskesmas suku yang paling banyak adalah Jawa(48,7\%).

Hasil univariat variabel penelitian pada kelompok ibu post partum di BPM lebih banyak berpengetahuan Baik (78,6\%). Pada kelompok ibu di Puskesmas lebih banyak ibu yang berpengetahuan kurang(61,5\%). Hasil penelitian ini didukung oleh penelitian Lanting tahun 2005 bahwa Persalinan bayi di rumah dikaitkan dengan tingkat inisiasi yang lebih tinggi serta durasi menyusui yang lebih lama dibandingkan dengan persalinan di rumah sakit. Bayi yang lahir setelah usia kehamilan 38 minggu, dengan berat lahir 3500 gr memiliki peluang lebih tinggi untuk disusui untuk periode yang lebih lama.

Hasil analisis bivariat variabel karakteristik responden(variabel konfounding) yang berhubungan dengan teknik penyusuan yang efektif adalah Pendidikan $(\mathrm{P}=0,034)$ dan Ekonomi (0,000), tetapi secara multivariat yang berperan sebagai variabel confounding/perancu adalah ekonomi. Hasil penelitian ini juga sama dengan penelitian yang dilakukan oleh Kishorel (2009) bahwa 60\% ibu melakukan ASI ekslusif sebagian besar dari menengah kebawah( 75\%).

Penelitian ini juga memperlihatkan bahwa ada hubungan yang signifikan $(\mathrm{P}=0,008)$ antara pengetahuan tentang menyusui dengan keefektifan teknik penyusuan. Hal ini sesuai dengan penelitian Kishore (2008) bahwa pengetahuan berhubungan signifikan $(\mathrm{P}=0,01)$ dengan posisi menyusui dan perlekatan bayi saat menyusui. Pengetahuan merupakan domain yang dangat penting untuk terbetuknya tindakan seseorang (Notoatmodjo, 2010)

Pengetahuan merupakan predictor untuk melihat keberhasilan menyusui Hal ini di dudukung oleh penelitian Handayani tahun 2014 menunjukkan ada hubungan pengetahuan dengan pemberian ASI Ekslusif $(\mathrm{P}=0,027)$, yaitu semakin baik pengetahuan maka semakin baik pula perilaku ibu dalam memberikan ASI ekslusif.

Hal serupa juga disampaikan dalam penelitian Bolling et al (2007) bahwa Sembilan dari sepuluh ibu berhenti menyusui lebih awal, Hanya tujuh dari sepuluh ibu yang diperlihatkan cara meletakkan bayi pada payudara pada beberapa hari pertama post partum oleh tenaga kesehatan, dan sepertiga dari jumlah ibu 
mengalami masalah penyusuan pada beberapa hari pertama post partum. Kurangnya pengetahuan dan ketrampilan para professional pelayanan kesehatan dalam mendorong para ibu untuk menyusui merupakan faktor yang berkontribusi besar terhadap rendahnya inisiasi dan durasi menyusui (Renfrew ddk, 2005)

Penelitian ini memiliki beberapa keterbatasan diantaranya adalah satu, keterbatasan sampel, tempat penelitian. Kedua keterbatasan informasi seperti konseling yang pernah ibu post partum dapatkan tentang teknik penyusuan, pengetahuan dan skill bidan yang memberikan pelayanan, yang merupakan beberapa faktor yang mempengaruhi teknik penyusuan yang efektif .

Kekuatan penelitian ini adalah tersedianya informasi faktor sosio demografi yang berhubungan dengan penyusuan. Oleh karena itu dapat di ketahui faktor konfounding yang mempengaruhi hubungan antara tempat persalinan dengan teknik penyusuan.

\section{KESIMPULAN}

1. Terdapat perbedaan yang signifikan $(\mathrm{P}=0,001)$ antara tempat persalinan dengan pengetahuan ibu menyusui, ibu postpartum di BPM yang berpengetahuan baik sebanyak $78,6 \%$ sedangkan yang di Puskesmas yang hanya $38,5 \%$

2. Karakteristik responden yang berhubungan dengan pengetahuan ibu post partum tentang menyusui adalah Pendidikan $(\mathrm{P}=0,01)$, Ekonomi, $\quad(\mathrm{P}=0,000)$ dan suku bangsa $(\mathrm{P}=0,019)$.

3. Tempat persalinan di Praktek Mandiri Bidan mempunyai peluang dalam peningkatan pengetahuan Asi Ekslusif ibu 3 kali dibanding bersalin di Puskesmas setelah dikontrol variabel Pendidikan.

\section{REFERENSI}

Ariwati VD, Rosyidi MI, Pranowawati P. 2014. Hubungan dukungan Bidan tentang Pemberian ASI ekslusif dengan perilaku pemberian ASI ekslusif di Wilayah Kerja Puskesmas Ambarawa Kabupaten Semarang. Semarang: Kepustakaan STIKES Ngudi Waluyo Ungaran.
Bolling, K., dkk. 2007. Infant Feeding survey 2005, London

De Cock TP, Mannien J, Geerts C, Klomp T, de Jonge. 2015. Exclusive breastfeeding after home versus hospital birth in primary midwifery care in the Netherlands. BMC Pregnancy and Childbirth, 15 (262): 118612884.

Handayani L, Yunengsih, Solikha. 2014. Hubungan pengetahuan dan teknik menyusui dengan pemberian ASI ekslusif di wilayah kerja Pengasih II kabupaten Kulon Krejo. Kesmasindo, vol 6 (2):23239.

Hutton EK, Reitsma AH, Kaufman K. 2009. Outcomes associated with planned home and planed hospital births in low-risk women attended by midwives in Ontario, Canada 2003-2006: retrospective cohort study. Birth, 36(3):180-9.

Kementerian Kesehatan RI, 2016. Profil Kesehatan Indonesia Tahun 2015. Jakarta: Kementerian Kesehatan Republik Indonesia.

Kementerian Kesehatan RI, 2014. Situasi dan Analisis ASI Ekslusif. Jakarta: InfoDatin Kemenkes RI.

Kishore, Kumar and Aggarwal. 2008. Breatsfeeding knowledge and practices amongst mothers in a rural population of North India: A community-based study. J.of tropical pediatrics, vol 55(3): 183-88.

Kronborg, H., \& Væth, M. (2009). How Are Effective Breastfeeding Technique and Pacifier Use Related to Breastfeeding Problems and Breastfeeding Duration?. BIRTH, vol 36(1) :34-42.

Lanting CI, Van Wouwe JP, Reijneveld SA 2005 Infant milk feeding practices in the Netherlands and associated factors. Acta Paediatr, vol 94(7):935-42.

Notoatmojo S. 2010. Kesehatan Masyarakat Ilmu dan Seni. Jakarta: Rineka Cipta

Nurhidayah. 2012. Hubungan pengetahuan ibu primipara tentang menyusui dan teknik menyusuidi Ruang rawat Inap Postnatal 
Heriza Syam, Jehanara, Nurdjasmi

Perbandingan Faktor-Faktor Yang Mempengaruhi Pengetahuan Tentang........

RSUP Fatmawati. Skripsi. Prodi Keperawatan Fakultas Ilmu Kesehatan Universitas pembangunan Nasional Veteran Jakarta. www.library.upnvj.ac.id/pdf/1010712036/ pdf
Pollard, M. 2014. ASI Asuhan Berbasis Bukti. Jakarta: EGC.

Renfrew, dkk. 2005. The Efectivrness of public health intervension to promote the duration of breastfeeding: Systematic review, London. 